Dilate Kardiyomiyopatinin Nadir Ancak Tedavi Edilebilir

Bir Nedeni Olan ALCAPA Sendromlu Altı Olgunun

Değerlendirilmesi

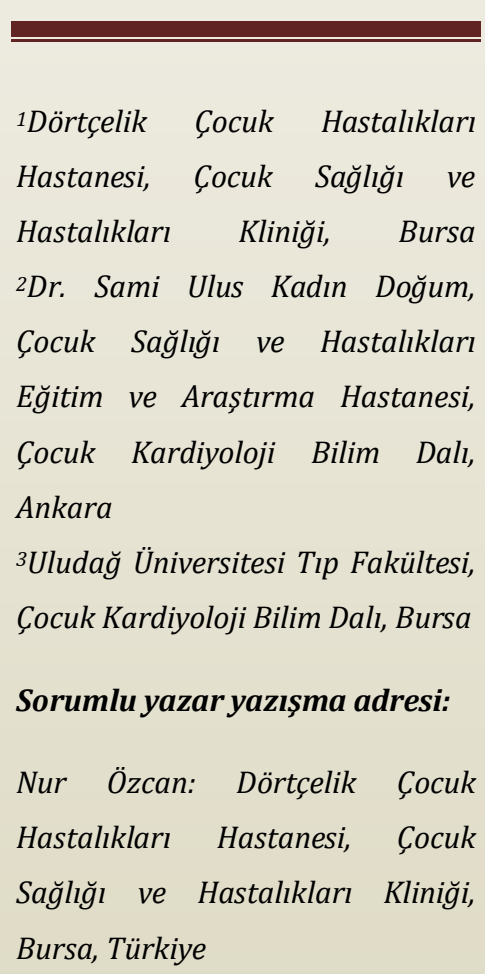

E-mail:drnur87@gmail.com

Geliş tarihi/Received: $\quad 19.09 .2020$ Kabul tarihi/Accepted: 01.12.2020 Yayın hakları Güncel Pediatri'ye aittir.

Güncel Pediatri2020;18(3):290-99

\section{Evaluation of Six Cases with ALCAPA Syndrome: a Rare but Treatable Cause of Dilated Cardiomyopathy}

Nur Özcan (0000-0001-6093-6263) ${ }^{\mathbf{1}}$, Metehan Kızlkaya (0000-0001-63325302) $)^{2}$, Tuğberk Akça (0000-0002-2747-974X) ${ }^{3}$, Özlem Mehtap Bostan (00000001-7707-2174) ${ }^{3}$

\section{$\ddot{O} Z$}

GİRIŞ ve AMAÇ: Sol koroner arterin pulmoner arterden köken aldığı ALCAPA (anomalousorigin of the left coronary artery from the pulmonary artery) sendromu, nadir görülen ve cerrahi tedavi ile düzelebilen bir doğuştan kalp anomalisidir. Tüm doğuştan kalp hastalıklarının \%0,250,50'sini oluşturmaktadır. Olgular yenidoğan döneminde genellikle semptomsuz seyrederler. Kalp yetersizliği semptomları olan olgularda dilate kardiyomiyopati (DKMP) ve mitral kapak yetersizliği (MY) saptanır. DKMP'nin nadir bir nedeni olan ALCAPA'da hayatın ilk yılında erken cerrahi tedavi ile prognoz oldukça iyidir. Cerrahi tedavi olmayan hastalarda mortalite yüksektir.

YÖNTEM ve GEREÇLER: Merkezimizde Ocak 2005-Aralık 2017 tarihleri arasında DKMP tanısı konulan ve etiyolojik değerlendirmede ALCAPA sendromu saptanan altı olgu retrospektif olarak değerlendirildi.

BULGULAR: Olguların 5'i kız, 1'i erkekti. Ortalama tanı yaşları 4,75 ay idi. Tüm olgularda başvuruda kalp yetersizliği bulgu ve semptomları mevcuttu. Olguların hepsinde elektrokardiyografide (EKG) D1, aVL ile göğüs derivasyonlarında iskemi bulguları mevcuttu. Olguların tümünde ekokardiyografide (EKO) sol ventriküldilatasyonu ile mitral yetersizlik saptandi. Tüm olgularda tanısal kateter anjiyografi ile ALCAPA tanısı doğrulandı. Tüm olgulara reimplantasyon yöntemi ile düzeltme ameliyatı yapıldı. Olguların 4'ü cerrahi tedavi sonrası tamamen düzeldi. Bir olgu operasyondan 5 gün sonra kaybedildi. Bir olgu ise cerrahi tedavi sonrası kardiyak fonksiyonlarında düzelme olmaması nedeniyle medikal tedavi ile izlenmektedir. 
TARTIŞMA ve SONUÇ: Dilatekardiyomyopati tanısı konulan olguların etiyolojisinde ALCAPA sendromu mutlaka düşünülmeli ve erken tanı ve tedaviyle tamamen iyileşebilen bir hastalık olduğu bilinmelidir.

Anahtar Kelimeler: Pulmoner arterden çıkan anormal sol koroner arter sendromu, ALCAPA sendromu, dilatekardiyomiyopati, kalp yetersizliği

\section{ABSTRACT}

INTRODUCTION: Anomalous origin of the left coronary artery from the pulmonary artery (ALCAPA) is a rare congenital cardiac anomaly that can be cured with surgical treatment. It accounts for 0.25 to $0.5 \%$ of all congenital heart diseases. ALCAPA is generally asymptomatic in the neonatal period. Dilated cardiomyopathy (DCM) and mitral valve insufficiency (MVI) are detected in patients with symptoms of heart failure. ALCAPA, which is a rare cause of DCM, early surgical treatment provides quite good prognosis in the first year of life. However, mortality is high in patientswho do not receive surgical treatment.

MATERIALS and METHODS: Six patients diagnosed with DCM at our clinic between January, 2005 and December, 2017 and detected with ALCAPA syndrome in their etiological assessment we reevaluated retrospectively

RESULTS: Of the 6 patients, 5 were female and 1 was male. The average age of diagnosis was 4,75 months. All patients had the signs and symptoms of heart failure at admission. All cases had the signs of ischemia in the chest leads, D1 andaVL in the electrocardiograms (ECGs). In al lcases, echocardiography (ECHO) showed mitral insufficiency and the dilation of the left ventricle and the mean ejection fraction was 29,3\% (18-39\%), and the mean shortening fraction was $12,6 \%(8-19 \%)$ in theECHOs. Diagnostic catheter angiography was performed for all patients and the diagnosis of ALCAPA was confirmed. All patients under went correction surgery with there implantation method. Four of the patients completely recovered after surgery. One patient died 5 days after the surgery. One patient is being followed up with medical treatment since there was no improvement in her cardiac functions after surgery.

CONCLUSIONS: The ALCAPA syndrome should definitely be considered in th eetiology of cases diagnosed with dilated cardiomyopathy and it should be kept in mind that ALCAPA is completely treatable disease with early diagnosis and treatment.

Key words: Anomalous origin of the left coronary artery from the pulmonary artery, ALCAPA syndrome, dilated cardiomyopathy, cardiac failure 


\section{GíRIŞ}

Sol koroner arterin pulmoner arterden çıktı̆̆ ALCAPA sendromu, 300.000 canlı doğumda 1 görülen nadir bir doğuştan kalp anomalisidir (1,2). İlk klinik tanımlama 1933’te Bland, White ve Garland tarafindan yapılmış olup bu anomali aynı zamanda Bland-White-Garland-Sendromu olarak da bilinmektedir (3). Olgular çoğunlukla kalp yetersizliği bulguları ile başvururlar (4). Bu nadir koroner arter anomalisinin, morbidite ve mortalitesinin yüksek olması ve cerrahi yöntem ile düzelebilen bir hastalık olması nedeniyle teşhis edilmesi çok önemlidir. Cerrahi tedavi yapılamayan hastalar \%90 oranında yaşamın ilk yılında kaybedilirler (5).

ALCAPA sendromunda doğumdan kısa bir süre sonra pulmoner arter basıncının düşmesi ile anormal yerleşimli sol koroner artere olan antegrad akım azalır ve miyokardiyaliskemi gelişir. Miyokardın oksijen tüketimi arttıkça zaman içinde miyokardiyaliskemi bulguları da derinleşir.

Hastalığın tipik klinik seyri pulmoner arter basıncının düştüğü yaşamın ilk 1-2 ayında ortaya çıkar. Olgularda beslenme güçlüğü, terleme, solukluk, irritabilite, takipne ve taşikardi gibi kalp yetersizliği bulguları saptanir.

$\mathrm{Bu}$ çalışmada merkezimizde ALCAPA sendromu tanısı konulan altı olgunun klinik bulguları, tanı, tedavi ve izlem sonuçları sunuldu.

\section{GEREÇ ve YÖNTEM}

Kliniğimizde Ocak 2005-Aralık 2017 tarihleri arasında DKMP tanısı konulan ve etiyolojik değerlendirmede ALCAPA sendromu saptanan altı olgu; tanı yaşı, cinsiyet dağılımları, başvuru semptomları, EKG, telekardiyografi, EKO, kardiyak kateterizasyon ve anjiyografi sonuçları, tedavi ve prognoz açısından retrospektif olarak değerlendirildi.

\section{SONUÇLAR}

Olguların 5'i kız, 1'i erkekti. Ortalama tanı yaşı 4,75 (2-11) ay ve ortalama vücut ağırlığı 5,1 (3-9) kg idi. Tüm olgularda kalp yetersizliği semptom ve bulguları mevcuttu. Olguların 1'ine tekrarlayan akciğer enfeksiyonu nedeniyle araştırılırken tanı konuldu. Tüm olgularda telekardiyografide kardiyomegali ve EKG'de D1 ve aVL'de derin Q dalgaları ile diğer göğüs derivasyonlarında ST depresyonu saptandı (Resim-1). Olgulara yapılan EKO incelemesinde; tüm olgularda sol ventriküldilatasyonu ve mitral kapak yetersizliği saptandı. Olguların sol ventrikülejeksiyon fraksiyonu (EF) ortalaması \%29,3 (18-39), kısalma fraksiyonu (KF) ortalaması \%12,6 (8-19) olarak ölçüldü. 


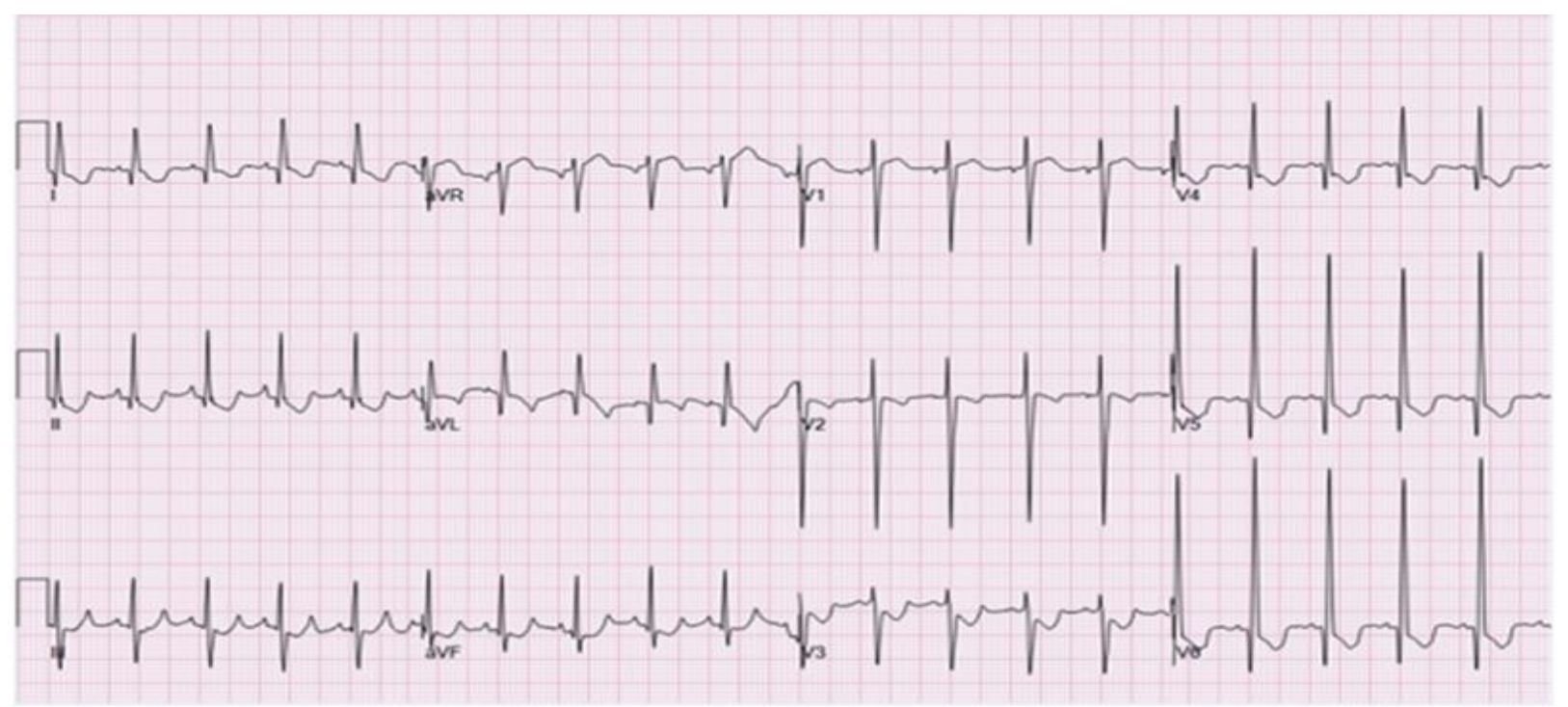

Figür 1: D1 ve aVL derivasyonlarında derin $Q$ dalgalarl, V5 ve V6'da sol ventrikül hipertrofisi bulgusu ile ST çökmesi ve T dalga inversiyonu görülmektedir.

Olguların 4'ünde renkli Doppler ile inter ventriküler septumda kollateral akımlar (Resim-2), 3 olguda papiller kaslarda ekojenite artışı ve 2 olguda sağ koroner arterde genişleme izlendi.

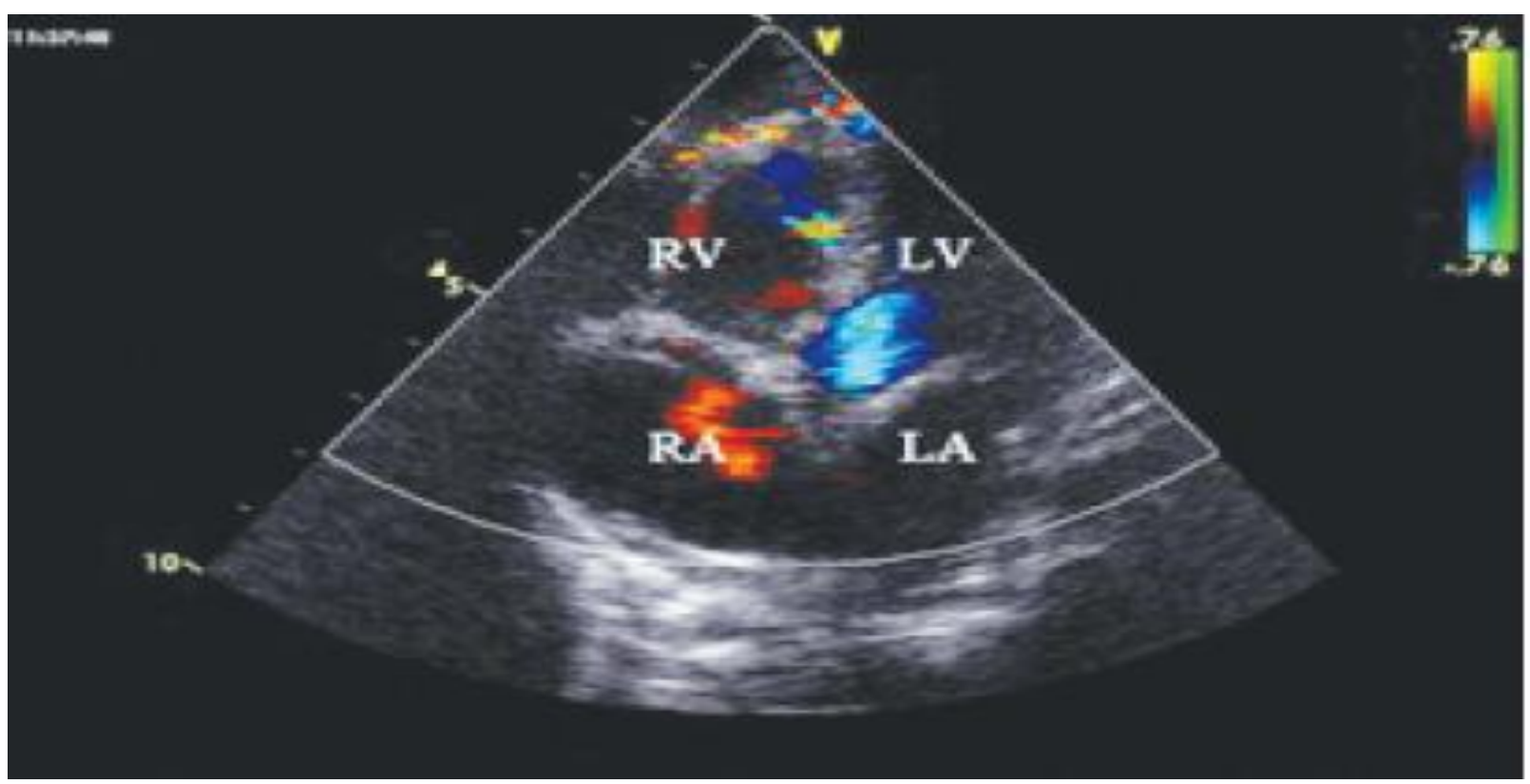

Figür 2: Apikal 4 boşluk renkli Doppler EKO’da inter ventriküler septum üzerinde çok sayıda koroner kollateral arterlere ait akımlar görülmektedir.

Tüm olgulara kateter anjiyografi yapıldı. Anjiyografide pulmoner arterden çıkan sol koroner arter saptand1 (Resim-3) 


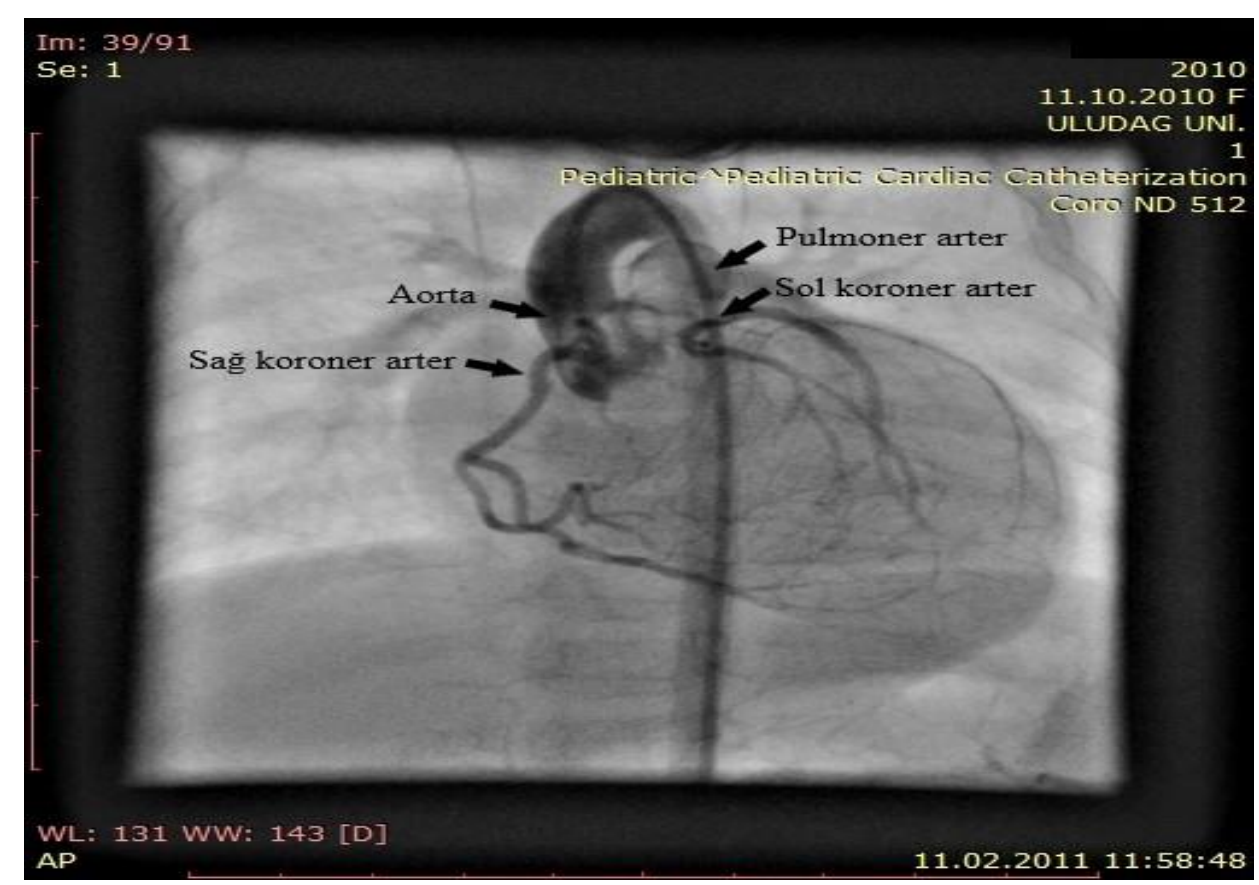

Figür 3: Anjiyografide pulmoner arterden köken alan sol koroner arter görülmektedir.

Tüm olgulara sol koroner arterin aort köküne reimplantasyonu yöntemi ile düzeltme ameliyatı yapıldı. Ortalama ameliyat yaşı $6(2-11,5)$ ay idi. Olguların düzeltme ameliyatı sonrası ortalama takip süresi 44,75 (0,1-104) aydı. Ameliyat sonrası 1 hasta kaybedildi. Olguların 4'ünün izlemde yapılan EKO kontrollerinde ventrikül fonksiyonlarında tamamen düzelme saptandı ve tedavileri kesildi. Bir olgunun ise sol ventrikül fonksiyonlarında düzelme olmadığ için medikal tedavi ile izlemine devam ediliyor. Olguların ortalama düzelme süresi 15,25 ay olarak saptand1. En erken düzelme 2 ay, en geç düzelme 33 ay olarak tespit edildi (Tablo-1). 
Tablo 1: ALCAPA sendromu olgularının demografik ve klinik özellikleri

\begin{tabular}{|c|c|c|c|c|c|c|}
\hline Olgu no & 1 & 2 & 3 & 4 & 5 & 6 \\
\hline Cinsiyet & K & K & $\mathrm{K}$ & K & $\mathrm{K}$ & E \\
\hline Tanı yaşı (ay) & 3,5 & 5 & 11 & 4 & 2 & 3 \\
\hline Semptomlar/Bulgular & $\begin{array}{l}\text { Dispne } \\
\text { KY bulguları }\end{array}$ & $\begin{array}{l}\text { Dispne KY bulguları } \\
\text { Sık akciğer } \\
\text { enfeksiyonu }\end{array}$ & KY bulguları & $\begin{array}{l}\text { Dispne } \\
\text { KY bulguları }\end{array}$ & $\begin{array}{l}\text { Dispne } \\
\text { KY bulguları }\end{array}$ & $\begin{array}{l}\text { Dispne } \\
\text { KY bulguları }\end{array}$ \\
\hline EKG & $\begin{array}{l}\text { D1-AVL de } \\
\text { Patolojik Q dalgası } \\
\text { ST yüksekliği }\end{array}$ & $\begin{array}{l}\text { D1-AVL de } \\
\text { Patolojik Q dalgası } \\
\text { ST yüksekliği }\end{array}$ & $\begin{array}{l}\text { D1-AVL de } \\
\text { Patolojik Q dalgası } \\
\text { ST yüksekliği }\end{array}$ & $\begin{array}{l}\text { D1-AVL de Patolojik } \\
\text { Q dalgası } \\
\text { ST yüksekliği }\end{array}$ & $\begin{array}{ll}\text { D1-AVL } & \text { de } \\
\text { Patolojik } & \text { Q } \\
\text { dalgası } & \\
\text { ST yüksekliği Sol } \\
\text { ventrikül } \\
\text { dilatasyonu }\end{array}$ & $\begin{array}{l}\text { D1-AVL de } \\
\text { Patolojik Q } \\
\text { dalgası } \\
\text { ST yüksekliği }\end{array}$ \\
\hline Telekardiyografi & Kardiyomegali & Kardiyomegali & Kardiyomegali & Kardiyomegali & Kardiyomegali & Kardiyomegali \\
\hline EKO & $\begin{array}{l}\mathrm{EF}=\% 24 \\
\mathrm{KF}=\% 11 \\
\mathrm{MY}=+3 \\
\mathrm{IVKA}=\mathrm{var} \\
\mathrm{PH}=\mathrm{yok}\end{array}$ & $\begin{array}{l}\mathrm{EF}=\% 34 \\
\mathrm{KF}=\% 10 \\
\mathrm{MY}=+2 \\
\text { IVKA= yok } \\
\mathrm{PH}=\mathrm{var}\end{array}$ & $\begin{array}{l}\mathrm{EF}=\% 18 \\
\mathrm{KF}=\% 8 \\
\mathrm{MY}=+2 \\
\text { İVKA= var } \\
\mathrm{PH}=\text { yok }\end{array}$ & $\begin{array}{l}\mathrm{EF}=\% 30 \\
\mathrm{KF}=\% 14 \\
\mathrm{MY}=+2 \\
\text { IVKA= var } \\
\mathrm{PH}=\text { yok }\end{array}$ & $\begin{array}{l}\mathrm{EF}=\% 39 \\
\mathrm{KF}=\% 19 \\
\mathrm{MY}=+4 \\
\text { IVKA= yok } \\
\mathrm{PH}=\mathrm{var}\end{array}$ & $\begin{array}{l}\mathrm{EF}=\% 31 \\
\mathrm{KF}=\% 14 \\
\mathrm{MY}=+1 \\
\mathrm{IVKA}=\mathrm{var} \\
\mathrm{PH}=\mathrm{var}\end{array}$ \\
\hline Kateter anjiyografi & ALCAPA & ALCAPA & ALCAPA & ALCAPA & ALCAPA & ALCAPA \\
\hline Ameliyat tekniği & Reimplantasyon & Reimplantasyon & Reimplantasyon & Reimplantasyon & Reimplantasyon & Reimplantasyon \\
\hline İzlem süresi ve verileri & $\begin{array}{l}30 \text { ay izlem } \\
\mathrm{EF}=\% 60 \\
\mathrm{MY}=+1\end{array}$ & $\begin{array}{l}53 \text { ay izlem } \\
\mathrm{EF}=\% 64 \\
\mathrm{MY}=+1\end{array}$ & $\begin{array}{l}22 \text { ay izlem } \\
\mathrm{EF}=\% 21 \\
\mathrm{MY}=+3\end{array}$ & $\begin{array}{l}104 \text { ay izlem } \\
\mathrm{EF}=\% 58 \\
\mathrm{MY}=+1\end{array}$ & $\begin{array}{l}\text { Operasyon sonrası } \\
\text { 5. günde eksitus }\end{array}$ & $\begin{array}{l}45 \text { ay izlem } \\
\mathrm{EF}=\% 70 \\
\mathrm{MY}=\text { yok }\end{array}$ \\
\hline Sonuç & İyileşme & İyileşme & Haliyle & İyileşme & Ölüm & İyileşme \\
\hline
\end{tabular}

ALCAPA: Anomalousorigin of theleftcoronaryarteryfromthepulmonaryartery, E: Erkek, EF: Ejeksiyon fraksiyonu, EKG: Elektrokardiyografi, EKO: Ekokardiyografi, IVKA: interventrikülerkollateraller akımlarl, K:Kız, KF: Kısalma fraksiyonu, KY: Kalp yetersizliği, MY: Mitral yetersizlik, PH: Papillerhiperekojenite

Ameliyat sonrası izlemde sol ventrikül fonksiyonlarında normale dönme süresi geciken iki olguya 2. kez kateter anjiyografi yapıldı ve koroner arterlerde anormallik saptanmadı. 


\section{TARTIŞMA}

ALCAPA sendromu, nadir görülen ancak tedavi edilmediğinde yaşamın ilk yıllarında yüksek mortaliteye sahip bir hastalıktır. Bu hastalığın patofizyolojik ve klinik özellikleri, sol ventrikül miyokardının zayıf perfüzyonuyla doğrudan ilişkilidir. Bu nedenle hastaların \%85'i yaşamın ilk 2-3 ayında semptomatik hale gelir. Hastaların \%15'inde klinik semptomlar erişkin yaşa kadar ortaya çıkmayabilir (1). Yapılan çalışmalarda $(7,9,15)$ olguların tanı yaş aralığı 3-54 ay olarak bildirilmiştir. Birkaç hasta ise yenidoğan döneminde tanı almıştır. Bazı çalışmalarda kız cinsiyette daha sık olduğu saptanmıştır $(7,15)$. Çalışmamızda ortalama tanı yaşı 4,75 (2-11) ay olarak tespit edildi. Olguların 5'i kız 1'i erkek idi. Konjestif kalp yetersizliği (KKY) bulguları nedeniyle hastalar genelde yaşamın ilk bir yılında tanı alır. Süt çocukluğu döneminde ağlama atakları, emmede azalma, çabuk yorulma, takipne gibi semptomlar; infantil kolik, gastroözafagialreflü ve bronşit gibi tanıları düşündürebilir (2). Yapılan bir çalışmada (4) bir olgunun 3 haftalıkken ani bebek ölümü nedeniyle yapılan otopsisinde ALCAPA sendromu tanısı aldığı ve daha önceki hastane başvurularında infantil kolik olarak değerlendirildiği bildirilmiştir. Aynı çalışmada olguların genellikle beslenmede azalma, gelişim geriliği ve huzursuzluk nedeniyle başvurduğu ve uzun süre kolik, gastroözafagialreflü olarak tedavi edildiği saptanmıştır. Diğer bir çalışmada ise (10) 28 günlükken başvuran bir hastada emerken morarma ve hızlı nefes alma gibi kalp yetersizliğini düşündüren bulguların saptanması üzerine yapılan anjiyografide ALCAPA sendromu saptanmış ancak ameliyat sonrası erken dönemde kaybedildiği bildirilmiştir. Olgularımızın hepsinde başvuruda KKY bulguları mevcuttu. Olguların 1'inde ise ek olarak tekrarlayan akciğer enfeksiyonu vardi.

DKMP hastalarında ALCAPA tanısını koymak çok önemlidir. Bu hastaların büyük çoğunluğu bir grup uzun süreli laboratuvar testlerine tabi tutulur. Bu durum tanı gecikmesinin en önemli nedenlerinden biridir. Diğer yandan DKMP hastalarında ALCAPA'yı düşündüren bazı ipuçları vardır. EKG'de D1, aVL ve V4-V6'da patolojik Q dalgaları saptanabilir (6). Yaygın kollateral akımı olan hastalarda EKG bulguları spesifik olmayabilir (1). Çalışmamızdaki olguların hepsinde EKG'de anterolateral derivasyonlarda miyokardiyaliskemi bulguları ve ST segmentinde çökme saptandı. EKO incelemesinde olguların çoğunda; sol ventriküldilatasyonu ve disfonksiyonu, papiller kas hiperekojenitesi, pulmoner arterde diyastolde retrograd akım, değişen derecelerde MY ve interventrikülerseptumdakollateral akımlara ait görüntüler saptandığı bildirilmiştir (14). Bir çalışmada ise olguların hepsinde sağ koroner arterin aortun çapına oranının normalden yüksek saptandığı belirtilmiştir (15). Çalışmamızda olguların hepsinde sol ventrikül dilatasyonu ve MY mevcuttu. Olguların 4'ünde inter ventriküler septumda kollateral akımlar, üç olguda papiller kaslarda ekojenite artışı ve 2 olguda sağ koroner arterde genişleme saptand1. Sol koroner arterin pulmoner arterden çıkış anomalisi günümüzde EKO cihazlarındaki çözünürlüğün artması ile daha erken tanınabiliyor olsa da başlangıçta olgular idiyopatik DKMP olarak bir süre izlenebilmektedir. Yapılan çalışmalarda bu oranlar sırasıyla \%75 ve \%78,3 olarak bildirilmiştir 
(15-16). Olguların tanı alana kadar geçirdikleri sürelere baktığımızda ilk çalışmada (15) 4 olgunun 3'üne sirasıyla; 3 gün, 3 ay ve 30 ay sonra tanı konulduğu bildirilmiştir. Çalışmamızda bir olgunun tanısı ilk başvurudan 2 ay sonra yapılan kateter anjiyografi ile konuldu. Diğer olgular ise EKG ve EKO değerlendirmesi ile ilk başvurularında tanı aldılar.

ALCAPA'nın tedavisinde birkaç farklı cerrahi yöntem uygulanmaktadır. Hepsindeki amaç, iki koroner arterli bir sistem oluşturmak ve sol ventrikül fonksiyonlarını düzeltmektir. En sık kullanılan yöntem sol koroner arterin aort köküne direkt reimplantasyonudur. Diğer bir yöntem ise aortopulmoner pencere oluşturarak kan akışının aorttan sol koroner artere yönlendirilmesidir (Takeuchi yöntemi). Bu uygulamalar sonrasında sol ventrikül fonksiyonları ne kadar bozulmuş olsa da miyokardiyal kanlanma hızla düzelebilmektedir (14). Jin ve ark.larının yaptıkları çalışmada (13) tüm olgulara reimplantasyon yöntemi uygulanmış ve hepsinde sol ventrikül fonksiyonlarının düzeldiği bildirilmiştir. Başka bir çalışmada (14) olguların 8'ine koroner reimplantasyon, diğer 2'sine Takeuchi yöntemi uygulanmış ve tüm olgularda sol ventrikül fonksiyonlarının normal düzeye geldiği görülmüştür. Uysal ve ark.larının çalışmasında (17) ise 7 ALCAPA tanılı olgunun 5'ine Takeuchi operasyonu, 2'sine reimplantasyon işlemi yapılmıştır. Takeuchi operasyonu ve reimplantasyon işlemi yapılan 1'er olgu postoperatif, diğer 1 olgu da preoperatif dönemde kaybedilmiştir. Çalışmamızda olguların hepsine reimplantasyon yöntemi uygulandi. Olguların 1'i operasyondan 5 gün sonra kaybedildi. Bir olgunun ise sol ventrikül fonksiyonlarında düzelme olmadi.

Sonuç: Dilatekardiyomiyopati tanısı konulan hastalarda etiyolojide ALCAPA mutlaka akla gelmeli ve EKO incelemesinde koroner arter çıkışları ve interventrikülerseptumdakollateral akımları dikkatli bir şekilde değerlendirilmelidir. Günümüzde gelişmiş cerrahi teknikler ve yoğun bakım şartları ile morbidite ve mortalite oldukça azalmıştır. Bu nedenle ALCAPA'nın erken tanı ve tedaviyle tamamen iyileşebilen bir hastalık olduğu bilinmelidir.

Çalışmanın Kısıtlılıkları: Çalışmamızın kısıtlı yanları, az sayıda olguyu içermesi ve retrospektif bir inceleme olmasidır.

Çıkar çatışması: Yoktur

Finansman desteği: Yoktur 


\section{KAYNAKLAR}

1. Yildiz CE, Binnetoglu $\mathrm{K}$ et al. A rare but treatablecause of dilatedcardiomyopathy: ALCAPA casereport. Yeditepe MedicalJournal2012;6:502-5.

2. Çiftel M, Ertuğ H. Anomalousleftcoronaryarteryarisingfromthepulmonaryartery. IKSST Derg 2014 6:109-12.

3. Kristensen T, Kofoed KF, Helqvist S, Helvind M, Sondergaard L. Anomalousorigin of theleftcoronaryarteryfromthepulmonaryartery (ALCAPA) presentingwithventricularfibrillation in an adult: A casereport. Journal of Cardiothoracic Surgery 2008;3:33.

4. Brotherton H, Philip RK. Anomalousleftcoronaryarteryfrompulmonaryartery (ALCAPA) in infants: a 5year review in a definedbirthcohort. Eur J Pediatr 2008;167:43-6.

5. Yam M-C, Menahem S. Mitral valvereplacementfor severe mitral regurgitation in infantswithanomalousleftcoronaryarteryfromthepulmonaryartery. Pediatr Cardiol1996;17:271-4.

6. Hoffman JIE. Electrocardiogram of anomalousleftcoronaryarteryfromthepulmonaryartery in infants. Pediatr Cardiol 2013;34:489-91.

7. Walsh MA, Duff D et al. A review of 15-year experiencewithanomalousorigin of theleftcoronaryartery. Ir J MedSci2008;177:127-30.

8. LangeR, Vogt M et al. Long-termresults of repair of anomalousorigin of the left coronary artery from the pulmonary artery. Ann Thorac Surg 2007;83:1463-71.

9. Florent C, Vouhe PR, Khoury W, et al. Anomalous left coronary artery arising from the pulmonary artery: A series of 27 infants under going operation in the firs tyears of life. J CardiothoracAnesth 1988; 4: 445-9.

10. Babaoglu K, Binnetoglu K, Altun G, Cetin G, Saltık L. A rarecause of dilated cardiomyopathy in the new born period: ALCAPA syndrome. TurkArchPed2011;46:256-8.

11. Michielon G, Di Carlo D, Brancaccio G, Guccione P, Mazzera E, et al. Anomalous coronary artery origin from the pulmonary artery: Correlation between surgical timing and left ventricular function recovery. AnnThoracSurg2003;76:581-8.

12. Lange R, Vogt M, Hörer J, Cleuziou J, Menzel A, et al. Long-termresults of repair of anomalousorigin of theleftcoronaryarteryfromthepulmonaryartery. AnnThoracSurg2007;8:1463-71.

13. Jin Z, Berger F, Uhlemann F, Schröder C, Hetzer R, Alexi-Meskhishvili V, et al. Improvement in leftventriculardysfunctionafteraorticreimplantation in consecutivepaediatricpatientswithanomalousorigin of theleftcoronaryarteryfromthepulmonaryartery. Earlyresults of a serialechocardiographicfollow-up. EurHeart J. 1994;15(8):1044-9.

14. Guzeltas A, Ozturk E, Tanidir CI, Kasar T, Haydin S. Evaluation of anomalouscoronaryarteriesfromthepulmonaryartery. Braz J CardiovascSurg2017;32:29-37. 
15. Ceylan Ö, Ürün UA ve ark. Pulmoner arterden çıkan anormal sol koroner arter: Dört olgu sunumuTürk Göğüs Kalp Damar Cerrahisi Dergisi 2013;21:122-6.

16. Zheng JY, Han L, Ding WH, Jin M, Zhang GZ, Xiao YY, et al. Clinicalfeaturesandlong-termprognosis of patientswithanomalousorigin of theleftcoronaryarteryfromthepulmonaryartery. ChinMed J (Engl) 2010;123:2888-94.

17. Uysal F, Bostan OM, Semizel E, Signak IS, Asut E, Cil E. Congenital anomalies of coronary arteries in children: The evalution of 22 patients. Pediatr Cardiol2014;35:778-84. 